\title{
Assessment of renal safety of tenofovir disoproxil fumarate in people living with HIV in Tunisia
}

\section{Abstract}

Background: Tenofovir disoproxil fumarate (TDF) is a nucleotide reverse transcriptase inhibitor (NRTI). TDF is generally well tolerated in the body. It is eliminated by glomerular filtration and active renal tubular secretion. So, it can be responsible for renal toxicity. The aim of our study is to assess the prevalence of TDF nephrotoxicity and its factors risk in people living with HIV (PLHIV) treated in the Infectious Diseases Department at the University Hospital of Monastir, Tunisia.

Methods: An observational cross-sectional single-centre prospective study included 62 cases of PLVIH taking antiretroviral therapy (ART) containing TDF was conducted between 1 August $1^{\text {st }} 2016$ and 31 December 2016 at Fattouma Bourguiba University Hospital of Monastir, in Tunisia. During this period, patients were screened for renal dysfunction to detect renal toxicity, Tubular dysfunction or Fanconi syndrome.

Results: 62 patients were included with male/female sex-ratio 1.58 (38 male). The age was (mean \pm SD) 39 years \pm 8.5 years. Half of the patients were treated with TDF as first-line therapy. The average duration of TDF was 25 months, the duration was greater than 12 months in $40(65 \%)$ patients. There was a decrease in creatinine clearance in $21(33.8 \%)$ patients, the average of the decrease was (mean \pm SD) $128.6 \pm 35.8 \mathrm{ml} / \mathrm{min}$. Proximal tubulopathy was noted in 1 patient (1.6\%) and no patient had Fanconi syndrome.

No risk factors for renal impairment under TDF were found. This finding could be explained by the small sample size

Conclusion: TDF-related renal toxicity is often asymptomatic, it requires early detection. In our patients, Tubular dysfunction (TD) is rare, but creatinine clearance decrease is frequent and may inform of possible TD in these patient. In order to reduce TDF toxicity, a new pro-drug, tenofovir alafenamide (TAF), is now available.
I. Kooli',

M. Ajroudi ${ }^{1}$,

A. Aouam ${ }^{1}$,

H. Ben Brahim',

C. Loussaief ${ }^{1}$,

A. Toumi ${ }^{1}$,

M. Chakroun ${ }^{1}$

1 Infectious Disease Department, Fattoumma Bourguiba Hospital, Monastir, Tunisia.

\section{Contact information:}

Dr. Ikbel Kooli.

Address: Infectious Disease Department, Fattoumma Bourguiba Hospital, 5000 Monastir, Tunisia.

”kooli.ikbel@gmail.com

Keywords

Tenofovir; HIV; Tunisian

Patients; Renal Safety. 


\section{Introduction}

The introduction of highly active antiretroviral therapy (HAART) has significantly reduced morbidity and mortality for PLHIV [1].

Tenofovir disoproxil fumarate (TDF) is a nucleotide reverse transcriptase inhibitor (NRTI). It is used in the first line-preferred regimen, currently recommended by WHO [2].

According to Tunisian recommendations, first-line antiretroviral therapy (ART) may include two reverse transcriptase inhibitors (NRTIs) associated with a ritonavir boosted protease inhibitor (PI/r) or two NRTI associated with an NNRTI. So, the combination of TDF with Emtricitabine (FTC) and efavirenz (EFV) is mostly used. Furthermore, TDF is part of the firstline ART combination in more than 144 countries particularly in middle and low incomes countries.

In addition to its effectiveness, TDF is characterized by its good tolerance. It is eliminated by the combination of glomerular filtration and active renal tubular secretion. Thus, it can lead to renal toxicity on the long or short terms.

This nephrotoxicity is estimated at less than 5\% in European studies. It is commonly asymptomatic and requires early detection and can be reversible after stopping TDF [3].

So, the main objective of our study is to assess the prevalence of TDF nephrotoxicity and risk factors in PLHIV followed at Monastir University Hospital in Infectious Disease Department.

\section{Methods}

This was an observational cross-sectional singlecentre prospective study involving 62 HIV-infected patients taking ART containing TDF. This study was conducted between 1 August 2016 and 31 December 2016.

During this period, patients were screened for renal dysfunction by urine dipsticks, serum creatinine, calcium level, glucose level, phosphate level and blood gases. Abnormalities were verified by a second sample. Demographic, medical and laboratory data was collected from case records.

Creatinine clearance $(\mathrm{CrCL})$ was calculated using the Cockroft-Gault equation, based on local practice patterns.

Tubular dysfunction (TD) was defined as having two or more characteristic features: decrease of $\mathrm{CrCL}$, positive glycosuria, proteinuria, urine phosphate level $>42 \mathrm{mmol} / \mathrm{l}$, tubular acidosis $(\mathrm{PH}<5)$ and decrease of serum phosphate level $<0.3 \mathrm{mmol} / \mathrm{L}$.

Fanconi syndrome was due to alteration in the resorption, which are specific for each of the substances reabsorbed in the proximal tubule. It was detected by developing glucosuria, phosphaturia, aminoaciduria, bicarbonaturia, and proteinuria, associated with urinary decrease in $\mathrm{Na}+/ \mathrm{K}+$, ATPase and ATP levels. [4]

To detect any abnormalities, we performed a descriptive and analytic study using SPSS 20.0.

\section{Results}

Sixty two patients were included, the male/female ratio was 1.58 . The mean age was 39 years \pm 8.5 years. Fourty eight patients $(77.4 \%)$ were aged between 30 and 50 years and 5 patients (8.1\%) were 50 years and older.

All the patients were treated with ART containing TDF. This last was prescribed as second line regimen on half of cases. This switch was due to failure in 10 cases $(32.2 \%)$ and to side effects in 5 cases (16.1\%). Only one patient was diabetic and no nephrotoxic medication was used by patients. TDF was used for a median duration of 19 months with a range of 10.5 -28 months. The characteristics of the population are shown in Table 1.

The mean of $\mathrm{CrCl}$ was $128.6 \pm 35.8 \mathrm{ml} / \mathrm{min}$ after mean duration of TDF use of 25 months. Fifty eight (93.5\%) had $\mathrm{Cr} \mathrm{Cl}$ more than $90 \mathrm{ml} / \mathrm{min}$. A decrease of $\mathrm{Cr} \mathrm{Cl}$ was noted on 21 patients (33.8\%) with a mean decrease of $19.8 \pm 17.8 \mathrm{ml} / \mathrm{min}$. Proteinuria 
Vol. 7 No. 3:1 doi: $10.3823 / 0811$
Table 1. Epidemiological, clinical and biological characteristics of 62 patients.

\begin{tabular}{|c|c|c|}
\hline Characteristics & Mean & $\begin{array}{l}\text { Standard } \\
\text { deviation }\end{array}$ \\
\hline Age (years) & 39 & 8.5 \\
\hline $\mathrm{BMI}(\mathrm{Kg})$ & 70 & 13.9 \\
\hline Initial creatinine $(\mu \mathrm{mol} / \mathrm{L})$ & 115.33 & 35.9 \\
\hline $\begin{array}{l}\text { Initial viral load } \\
\text { (copies/mL) }\end{array}$ & 1544628.167 & 7250708.739 \\
\hline $\begin{array}{l}\text { Initial CD4 count } \\
\left(\text { cells } / \mathrm{mm}^{3}\right)\end{array}$ & 291 & 296 \\
\hline $\begin{array}{l}\text { Undetectable viral load } \\
\text { due to TDF (patients) }\end{array}$ & 55 & \\
\hline
\end{tabular}

Table 2. Biological results for renal dysfunction.

\begin{tabular}{|l|c|c|c|}
\hline \multicolumn{1}{|c|}{ Characteristics } & Mean & $\begin{array}{c}\text { Standard } \\
\text { deviation }\end{array}$ & $\begin{array}{c}\text { Pathologic } \\
\text { cases }\end{array}$ \\
\hline $\begin{array}{l}\text { Creatinine clearance } \\
\text { (ml/min) }\end{array}$ & 128.64 & 35.88 & 4 \\
$\begin{array}{l}\text { Decrease of creatinine } \\
\text { clearance (ml/min) }\end{array}$ & 19.8 & 17.8 & 21 \\
\hline $\begin{array}{l}\text { Phosphate Serum level } \\
\text { (mmol/L) }\end{array}$ & 0.93 & 0.17 & 0 \\
\hline $\begin{array}{l}\text { Phosphate urine level } \\
\text { (mmol/L) }\end{array}$ & 18.25 & 9.37 & 2 \\
\hline $\begin{array}{l}\text { Urine pH } \\
\text { Urine glucose level }\end{array}$ & - & - & 0.31 \\
\hline Proteinuria & - & - & 0 \\
\hline
\end{tabular}

The univariate analysis didn't show any risk factors of tubular defect.

was common, found in 10 cases (16.1\%) of the entire cohort. Two patients (3.2\%) had urine phosphate more than $42 \mathrm{mmol} / \mathrm{L}$. All others biological characteristics were normal (Table 2).

Tubular dysfunction was detected in one patient (1.6\%). A 38-year-old female without medical history. She had been treated with TDF for 8 months. She hadn't any nephrotoxic medication. Her kidney ultrasound was normal and her CD4 count is 489 cells $/ \mathrm{mm}^{3}$. No cases of Fanconi syndrome were detected. All the abnormalities were shown in Table 2.

\section{Discussion}

TDF, the first approved oral prodrug of tenofovir, has been used in combination ART for the treatment of HIV-1 infection since 2001 [5]. It is generally well tolerated. However, TDF may cause an acute renal failure. In the literature, TDF toxicity accounted for $2.5 \%$ to $11 \%$ of cases [6]. The main TDF-related toxicity is a proximal tubular dysfunction, while altered GFR and progressive advanced renal disease. This toxicity was reported with a discordant outcomes. The mechanism of TDF kidney damage is unclear. Two assumptions were made, mitochondrial toxicity and direct interference with epithelial cells of the renal tubular function.

This nephrotoxicity is proximal tubulopathy with proteinuria, hypophosphatemia and Fanconi syndrome (tubular acidosis) occurred rarely.

Renal toxicity may be a decrease of creatinine clearance, a tubular defect or Fanconi syndrome. All these manifestations are related to a tubular cells dysfunction. TDF is toxic for mithochondrial function. So, cells don't produce energy and can't provide its usual function. Thus, resorption and secretion are altered. This hypothesis was confirmed by detection of ultrastructral anomalies for PLHIV treated with TDF. Its frequency increase with TDF use. It is estimate for about 1.5/1000 patients-year [6].

Many chemical abnormalities may detect renal toxicity. Such as decrease of Creatinine clearance, positive glycosuria, proteinuria, urine phosphate level, tubular acidosis $(\mathrm{PH}<5)$ and decrease of serum phosphate level [7].

Decrease of creatinine clearance after TDF using is frequently reported in literature and can achieve $13.3 \mathrm{~mL} / \mathrm{min}$. Creatinine clearance less than $70 \mathrm{~mL} /$ min is noted in 5/1000 patients-years. In our study decrease of creatinine clearance was noted in 21 patients (33.8\%). The mean value was $19.8 \mathrm{ml} /$ $\min \pm 17.8 \mathrm{~mL} / \mathrm{min}$. This renal toxicity is reversible after stopping TDF [6]. In our study, no patients stopped TDF. 
Also, TDF can be responsible for tubular dysfunction. So, there is decrease of serum phosphate level, positive glycosuria, proteinuria and urine phosphate level. These abnormalities may exist with normal creatinine [6].

This tubular dysfunction is associated with some histological features. We obviously note acute proximal tubular necrosis. But the main characteristic feature is to have broad eosinophilic inclusion [8]. An increase in tubular dysfunction in patients on TDF-based ART is noted in some European and African studies. It frequency is between 7 to $22 \%$ [9]. In our study, we identified one patient (1.6\%) with tubular dysfunction. TDF was identified responsible for this tubular dysfunction because the patient doesn't take any other treatment and doesn't have any other diseases which explain renal defect.

Fanconi syndrome is rarely reported in literature [3]. Its frequency is less than $5 \%$. Its diagnosis can be established after a polyuria-polydipsia syndrome, asthenia, arthralgia and myalgia. Occasionally Fanconi syndrome may can be diagnosed clinically, TDF related Fanconi syndrome can be diagnosed after a mean duration of 10 months (1 to 24 months) of using TDF .This syndrome is reversible after stopping the drug [4]. However, in some severe cases, we must use hemodialysis or renal transplantation. No case of Fanconi syndrome was noted in our study.

Many risk factors are detected in studies. So renal failure before treatment, low body mass index, diabetes and CD4 count less than 20 cells/mm3 were identified to be associated to renal toxicity related to TDF $[10,11]$.

Also, protease inhibitors or didanosine use with TDF may increase renal toxicity. In these cases Fanconi syndrome was noted more than 40\% [12].

But, the main risk factor for renal toxicity is TDF duration of use,-toxicity is more frequent if TDF duration is more than 12 months [6].

In our study, we didn't note any risk factors. These findings were explained by small sample of patients. Weaknesses of this study include TDF duration was relatively short, especially 40 patients were treated with TDF for 12 months. Also, the relatively small sample of patients who were tested for features of tubular dysfunction limited the power of the analyses to demonstrate correlations of postulated risk factors for TD. Finally, our population is too young which explains absence of a previous medical history and the use of toxic drugs. Recently, Tenofovir alafenamide (TAF) was found safer with similar efficiency to TDF [13]. This drug can be used in patient with renal failure and creatinine clearance less than $60 \mathrm{ml} / \mathrm{min}$ [14].

\section{Conclusions}

In summary this study showed that renal toxicity is common amongst Tunisian PLHIV taking ART. TDF was associated with toxicity. Monitoring of renal function (twice per year) and excluding high risk patients for renal injury is recommended.

\section{References}

1. Sterne JA, May M, Costagliola D, Wolf F, Phillips AN, Harris R et al. Timing of initiation of antiretroviral therapy in AIDS- freeHIV-1- infected patients: A collaborative analysis of $18 \mathrm{HIV}$ cohort study. When to start consortium. Lancet 2009; 373: 1352-63.

2. World health Organisation. The use of antiretroviral drugs for treating and preventing HIV infection. June 2016.

3. Highleyman L. Risk factors for kidney toxicity, in patients taking Tenofovir. Glasgow: UK-CAB 2007; 16: 12-6.

4. M. Ondounda, A. Tanon, E. Ehui, I. Ouattara, A. Kassi, Y.T. Aba, E.F. Aoussi, A.R. Kakou, S.P. Eholié, E. Bissagnene, A. Kadio . Le syndrome de Fanconi induit par le ténofovir en Afrique: deux cas en Côte d'Ivoire ". Med Mal Infect 2011:41:105.

5. Nelson MR, Katlama C, Montaner JS, Cooper DA, Gazzard B, Clotet $B$. The safety of tenofovir disoproxil fumarate for the treatment of HIV infection in adults: the first 4 years. AIDS 2007; 21: $1273-81$.

6. Isnard-Bagnis C, Aloy B, Deray G, Tourret J. Tenofovir nephrotoxicity. Nephrol et Therap 2016; 12: 179-89.

7. Winston A, Amin J, Mallon P, Marriott D, Carr A, Cooper DA. Minor changes in calculated creatinine clearance and anion-gap are associated with tenofovir disoproxil fumarate-containing highly active antiretroviral therapy. HIV Med 2006; 7: 105-11. 
8. Herlitz LC, Mohan S, Stokes MB, Radhakrishnan J, D'Agati VD, Markowitz GS. Tenofovir nephrotoxicity: acute tubular necrosis with distinctive clinical, pathological, and mitochondrial abnormalities. Kidney Int 2010; 78: 1171-7.

9. David R. Chadwick, Fred S. Sarfo, Elaine S. M. Kirk, Dorcas Owusu, George Bedu-Addo, Victoria Parris and al. Tenofovir is associated with increased tubular proteinuria and asymptomatic renal tubular dysfunction in Ghana. BMC Nephrol 2015; 16 : 195.

10. Ryom L, Mocroft A, Kirk O, Worm SW, Kamara DA, Reiss P, et al. Association between antiretroviral exposure and renal impairment among HIV-positive persons with normal baseline renal function: the D:A:D study. J Infect Dis 2013; 207: 1359-69.

11. Madeddu G, Bonfanti P, De Socio GV, Carradori S, Grosso C, Marconi P. Tenofovir renal safety in HIV-infected patients: results from the SCOLTA Project. Biomed Pharmac- other 2008; 62: 6-11.

12. Nishijima T, Komatsu H, Gatanaga H, Aoki T, Watanabe K, Kinai E. Impact of small body weight on tenofovir-associated renal dysfunction in HIV-infected patients: a retrospective cohort study of Japanese patients. PLoS One 2011; 6: 22661.

13. Gupta SK, Eustace JA, Winston JA, Boydstun II, Ahuja TS, Rodriguez RA. Guidelines for the management of chronic kidney disease in HIV-infected patients: recommendations of the HIV Medicine Association of the Infectious Diseases Society of America. Clin Infect Dis 2005; 40: 1559-85.

14. L. Cotte, C. Katlama, F. Post, A. Clarke, W. Short, M. Das, M. Fordyce, Tolérance à plus long terme du ténofovir alafénamide chez l'insuffisant rénal. Med Mal Infect 2016; 46: 117-27.

\section{Publish in The International Arabic Journal of Antimicrobial Agents}

The Journal is an open access peer-reviewed journal that publishes scientific papers about all aspects of antimicrobials. The journal will publish original research articles, reviews, brief reports and case reports dealing with basic and clinical antibacterial agents, antiviral, antiprotozoals, antituberculuous, antifungal and antihelminthes agents. All manuscripts must be prepared in English, and are subject to a rigorous and fair peer-review process. Accepted papers will immediately appear online. The journal aims to advance the knowledge, attitude and the research of chemotherapy in the Arabic world in cooperation with international, national scientific and public societies as well as research centers with similar aims and objectives. 